\section{It's not the law}

$M$ alvinder Parmar's Clinical Vistas article $^{1}$ illustrates a Courvoisier gallbladder handsomely. Parmar aptly and carefully notes the occurrence of exceptions, whereby nothing more ominous than cholelithiasis and chronic cholecystitis underlie painless jaundice with a palpable gallbladder. Thus, for clarity, we should stop calling the sign of Courvoisier a "law," which by definition must apply to all. This point is made in a wonderful short review of the phenomenon, and of Courvoisier's important place in the history of medicine, which was published 17 years ago by Verghese and associates. ${ }^{2}$

\section{Henry Schneiderman \\ Hebrew Health Care \\ University of Connecticut School of Medicine \\ West Hartford, Conn.}

\section{References}

1. Parmar MS. Courvoisier's law. CMA7 2003;168 (7):876-7.

2. Verghese A, Dison C, Berk SL. Courvoisier's "law" - an eponym in evolution. $A m \mathcal{F}$ Gastroenterol 1987;82:248-50.

DOI:10.1503/cmaj.1040574

\section{[The author responds:]}

Tagree that, because of the exceptions, 1 Courvoisier's law ${ }^{1}$ is not really a law. In the truest sense of the word, laws are rules created by the state or the courts, not medical observations. This particular observation has also been referred to as Courvoisier's sign ${ }^{2}$ and Courvoisier's gallbladder, ${ }^{3}$ but none of the terms were coined by Courvoisier.

Over a century ago, in 1890, Courvoisier presented his observation that a palpable gallbladder in a patient with obstructive jaundice is often caused by a noncalculus abnormality of the hepatobilliary system (e.g., pancreatic cancer or stricture of the common bile duct). He qualified this observation by stating that "if further evidence of this can be found, this would be an important marker for differential diagnosis." At what point the observation came to be referred to as a "law" is not clear, but it was acclaimed as such as early as 1905.5 More exceptions were noted later, which eventually led to skepticism about the "law," although most studies that have examined its validity ${ }^{6}$ have confirmed the general trend of Courvoisier's observation. Chung ${ }^{3}$ observed that high-grade obstruction of the common bile duct over a prolonged period (which is likely with pancreatic carcinoma but can also occur with stones) is responsible for dilatation of the gallbladder in patients with obstructive jaundice, and this theory would explain the various exceptions to Courvoisier's gallbladder that have been noted in the literature. Verghese and Berk ${ }^{7}$ suggested that "Clarity might be restored to this murky field by changing the eponym to 'Courvoisier's gallbladder.'”

There is no consensus on the proper eponym for this observation, but this has become an academic exercise because technological advances and early interventions in patients with gallstones or jaundice mean that the problem is usually addressed before it reaches this stage.

\section{Malvinder S. Parmar}

Medical Director (Internal Medicine)

Timmins and District Hospital

Timmins, Ont.

\section{References}

1. Parmar MS. Courvoisier's law. CMA7 2003;168 (7):876-7.

2. Fournier AM, Michel J. Courvoisier's sign revisited: two patients with palpable gallbladder. South Med 7 1992;85(5):548-50.

3. Chung RS. Pathogenesis of the "Courvoisier gallbladder." Dig Dis Sci 1983;28(1):33-8.

4. Verghese A, Dison C, Berk SL. Courvoisier's law - an eponym in evolution. Am $\mathcal{F}$ Gastroenterol 1987;82:248-50.

5. Moyniham BGA. Gallstones and their surgical treatment. 2nd ed. Philadelphia: WB Saunders; 1905.

6. Mikal S, Campbell AJA. Cancer of the pancreas: diagnostic and operative criteria based on 100 consecutive autopsies. Surgery 1950;28:963-7.

7. Verghese A, Berk SL. Courvoisier's law [letter]. Lancet 1986;1(8472):99.

DOI:10.1503/cmaj.1040939

\section{Time management}

T ere are some additional timemanagement suggestions to add to those of John Crosby. ${ }^{1}$ If a patient has more than 3 prescriptions, I use a square of carbon paper to copy my script directly into the chart. A bonus of this system is that it provides evidence for the not-infrequent disputes with pharmacies over number of refills and other aspects of the prescriptions. And for the one patient who is using a large number of herbs, vitamins, medications and shampoos, I have a preprinted large-size script page listing all of the items; at any particular visit, I simply initial the items requested.

\section{Ralph M. Jones}

Department of Family Practice

University of British Columbia

Vancouver, BC

\section{Reference}

1. Crosby JW. Ten time-management tips for family physicians. CMA7 2004;170(6):949-50.

DOI:10.1503/cmaj.1040668

Thave 2 suggestions to add to John 1 Crosby's time-management tips for physicians. $^{1}$

Preprinted problem lists, with their myriad columns for patient data such as cholesterol level and date of most recent mammogram, promise better organization of information, but physicians would be better off throwing these directly in the garbage. A rule of thumb is "The more complicated the form, the less likely you are to bother filling it out." Instead, take a blank sheet of paper and write the patient's name at the top. Down the left-hand side list the patient's medical problems, and across from each problem, on the right-hand side of the page, list the medications prescribed. At the bottom of the page, list any medication allergies. Make this page the first page of the patient's chart, facing inward to save flipping back and forth. Any patient who is receiving more than one medication should have a problem list like this.

My second suggestion relates to eliciting wheezing in patients with asthma. Some patients find it difficult to understand the physician's instructions to blow out forcefully, and for small chil- 